\title{
Water hardness influenced variations in reproductive potential of two freshwater fish species; Poecilia reticulata and Betta splendens
}

\author{
Abarna Krishnakumar ${ }^{1}$, E. S. Patrick Anton ${ }^{1}$ and Uthpala A. Jayawardena ${ }^{2^{*}}$ (1)
}

\begin{abstract}
Objective: Hardness of water in the form of $\mathrm{CaCO}_{3}$ affects reproductive potential in various fish species, differently. This study evaluates the effect of water hardness on growth and reproduction of two aquarium fishes, Poecilia reticulata (Ovo-viviparous sp.) and Betta splendens (Oviparous sp.) by growing them under 150 (control), 320, 540 and 900 ppm $\mathrm{CaCO}_{3}$ levels in semi natural aquaria.

Results: Growth increased with increasing water hardness, reporting a significant progress of $P$. reticulata $(p=0.005)$ at $900 \mathrm{ppm}$. Similarly, the reproductive potential of P. reticulata was improved significantly, recording the highest fecundity (16.22 \pm 3.90 ) and Gonadosomatic Index (GSI-2.48 \pm 0.6 ) at 900 ppm. However, in B. splendens water hardness adversely affected the reproduction by resulting a significantly low hatchability and disturbed bubble nests at 900 ppm, compared to the largest bubble nest formed at the control condition $\left(108.58 \pm 16.19 \mathrm{~cm}^{2}\right)$. Thus, the study revealed differential effects of water hardness on reproductive potential of the test species, by increasing the potential of $P$. reticulata while decreasing that of $B$. splendens. Though larval survival was affected in both species, larval growth was improved significantly in $P$. reticulata at $900 \mathrm{ppm}$ level. Understanding reproductive potential of aquarium fishes in natural waters is crucial for their management purposes.
\end{abstract}

Keywords: Water hardness, Freshwater fish, Fecundity, Gonadosomatic index, Growth performance

\section{Introduction}

Water hardness i.e., a measure of calcium $\left(\mathrm{Ca}^{2+}\right)$, magnesium $\left(\mathrm{Mg}^{2+}\right)$ and/or iron $\left(\mathrm{Fe}^{2+}\right)$ in water, is crucial for the growth, reproduction and embryo development of fish [1-4]. It affects oviparous and ovoviviparous fishes differently due to variations in their requirement of $\mathrm{CaCO}_{3}$ in the reproduction and growth $[1,5-8]$. Considering the importance of hardness in the early life stage processes such as hatchability, larval growth and survival of eggs, it is recommended to maintain the water hardness above $20 \mathrm{ppm} \mathrm{CaCO}_{3}[9,10]$.

*Correspondence: uajay@ou.ac.lk

2 Department of Zoology, Faculty of Natural Sciences, The Open

University of Sri Lanka, Colombo, Sri Lanka

Full list of author information is available at the end of the article
Water hardness in Vavuniya District, of the Dry Zone of Sri Lanka reports remarkably high values, such as 900-1000 ppm [11]. In Vavuniya, ornamental fish trade is mainly dependent on ground water. Thus, evaluating the effect of higher hardness on fish health is of prime economic and ecological importance.

Freshwater species, Poecillia reticulata (Guppy) and Betta splendens (Siamese fighting fish) were popular verities in the aquarium fish trade. $P$. reticulta produces eggs that are hatched within the body (ovoviviparous, live bearers) and the hatchlings are born inside the female while B. splendens lay eggs in a foam nest (oviparous, egg layers) for external fertilization. Both species, can be easily reared and bred under laboratory conditions.

This study evaluates the effect of different water hardness on (i) the growth performance of adults and larvae,

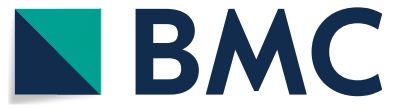

(c) The Author(s) 2020. This article is licensed under a Creative Commons Attribution 4.0 International License, which permits use, sharing, adaptation, distribution and reproduction in any medium or format, as long as you give appropriate credit to the original author(s) and the source, provide a link to the Creative Commons licence, and indicate if changes were made. The images or other third party material in this article are included in the article's Creative Commons licence, unless indicated otherwise in a credit line to the material. If material is not included in the article's Creative Commons licence and your intended use is not permitted by statutory regulation or exceeds the permitted use, you will need to obtain permission directly from the copyright holder. To view a copy of this licence, visit http://creativeco mmons.org/licenses/by/4.0/. The Creative Commons Public Domain Dedication waiver (http://creativecommons.org/publicdomain/ zero/1.0/) applies to the data made available in this article, unless otherwise stated in a credit line to the data. 
(ii) the reproductive potential and (iii) larval survival of two aquarium fish species, $P$. reticulata and $B$. splendens under semi-natural aquaria.

\section{Main text \\ Methods \\ Preparation of aquaria}

Glass aquaria of the size of $25 \times 13 \times 12 \mathrm{~cm}^{3}$ (24 tanks), simulating natural pond environment were used for the exposure. Being an aggressive fish, male B.splendens were kept individually in 20 separate cubic aquaria $\left(12 \times 12 \times 12 \mathrm{~cm}^{3}\right)$.

The experiment was composed of control (tap borne water $150 \mathrm{ppm} \mathrm{CaCO}_{3}$ ) and three treatment setups; 320, 540 and $900 \mathrm{ppm}$ prepared by adding analytical grade $\mathrm{CaCO}_{3}$ to aged tap water. This series was selected to cover the hardness range, $100-1000 \mathrm{ppm}$ in Vavuniya [8]. The hardness was determined by EDTA titration [12] and the treatment setups were screened weekly to maintain the relevant conditions. All the experiments were conducted as per the guidelines given by the research review panel of the Department of Bioscience, University of Jaffna.

\section{Introduction of fishes to aquaria and maintenance}

Healthy male and female fishes of $P$. reticulata and $B$. splendens were purchased from a nearby aquarium in Vavuniya and were transferred to the laboratory. Sexing was done by examining external morphology, where male fishes of both species possessed narrow and bright colored bodies and colorful caudal fins compared to round bellies and short caudal fins of the female fishes, displaying sexual dimorphism. Initial weight and standard length were measured, reporting $0.487 \pm 0.008 \mathrm{~g} / 2.98 \pm 0.05 \mathrm{~cm}$ for $P$. reticulata and $1.266 \pm 0.072 \mathrm{~g} / 3.5 \pm 0.01 \mathrm{~cm}$ for B. splendens. Then the fishes were acclimatized to aquarium condition (20 min. in each setup) and introduced to the experimental setups, $150 \mathrm{ppm}$ (control), 320, 540 and $900 \mathrm{ppm} \mathrm{CaCO}_{3}$ and reared for $1 \frac{1}{2}$ month. In each experimental setup 15 females were introduced to 5 males of B. splendens, separately. For, P. reticulata, 25 females were introduced to 5 males. The exposure was conducted with three replicates.

Feeding (5\% of the total body weight) was done twice a day at ad libitum with commercial fish pellets. The aquaria were maintained to keep the temperature $25-27{ }^{\circ} \mathrm{C}$ and $\mathrm{pH} 6.5-7.5$ by replacing the media with newly prepared hard water on weekly basis. Debris was siphoned out. Mild aeration level was maintained as the fishes are air breathers.

\section{Determination of growth performance}

Weight and length of adult fish were measured at the sexual maturation, and the length weight relationship was analyzed, using $\mathrm{W}=\mathrm{a}$ TLb: $(\log \mathrm{W}=\log \mathrm{a}+\mathrm{b} \log$ TL) [13] to obtain the linear regression.

\section{Determination of reproductive potential}

Female fishes showing gravid spots (Oocyte stage IIIIV) $(\mathrm{N}=6$ per dose for each sp.) were randomly tested for fecundity (the number of ripening eggs found in the female just prior to spawning) and GSI (the ratio of fish gonad weight to body weight). Euthanizing was conducted with $0.02 \%$ MS222 solution.

\section{Reproductive potential of B. splendens}

To estimate the bubble nest size of $B$. splendens, three sets of clean breeding aquaria (size-60 $\left.\times 30 \times 30 \mathrm{~cm}^{3}\right)$ were prepared without artificial bottom stones and aeration. A floating plant leaf was placed on the air water interface to facilitate the nest formation. After placing the male fish a clean glass cube containing a female fish was placed near the breeding aquarium to stimulate the nest building. Then the bubble nests built by male $B$. splendens $(\mathrm{N}=5)$ were measured (diameter) by a ruler [14].

Hatchability of $B$. splendens was estimated after allowing a successful courtship with a gravid female. Without disturbing the bubble nest, the number of eggs released was counted. After a successful mating female was removed, and male was allowed for $24-48 \mathrm{~h}$ pre hatched parental care. Next, the hatched larvae were counted, and the hatchability was determined, as the number of larvae hatched over the total number eggs [15].

\section{Reproductive potential of $P$. reticulata}

Fertility of $P$. reticulata was determined by counting the intra-follicular embryos inside the female by sacrificing few fishes $(\mathrm{N}=6)$ at the 21st day after mating [16]. The breeding tank for $P$. reticulata was formed with artificial aquarium stones and Vallisneria (a common water plant) to provide hiding place for the young ones. After the brooding parents were removed, and the hatchlings were counted.

\section{Larval survival}

Larval survival rate of both species $(\mathrm{N}=20-30$ per dose for each sp.) was determined after 1 week of exposure by counting the number of surviving one weeks-old larvae divided by the total number of hatched larvae/released young ones [15]. The larval growth performance $(\mathrm{N}=12$ 
per dose for each sp.) was estimated in every 10 days interval by measuring their length gain.

\section{Statistical analyses}

Normality of the data set was tested before applying the statistics with SPSS 20.0 (IBM, USA).

Homogeneity and independence were tested for applying parametric analyses. One-way ANOVA and Tukey pairwise comparison were conducted to analyse the effects on weight, standard length, fecundity and Gonadosomatic Index, Laval growth (length) of the fishes. The linear regression analysis was used to find the length weight relationship (LWR). In LWR linear regression analysis, the slope of regression lines explicit the exponent coefficient value ' $b$ '. Variations in the estimates of ' $b$ ' for the fish species, examined from the expected value (ideal value ' $b$ ' $=3$ ) were tested by t-test $[17,18]$. Students $\mathrm{t}$-test was applied to analyze the variation i.e. derived by dividing the difference between ' $\mathrm{b}$ ' and ' 3 ' by standard error of 'b' [19].

\section{Results}

Growth performance of exposed fishes

Growth improved with the increasing water hardness by showing significantly high weight values, particularly above $540 \mathrm{ppm}$ treatments $(\mathrm{p}<0.05)$, reaching $80 \%$ and $40 \%$ weight gains, respectively for $P$. reticulata $(\mathrm{N}=30)$ and B. splendens $(\mathrm{N}=20)$ in the highest hardness level (900 ppm). Similarly, length values of the both species were also increased with higher hardness levels, though only $14-17 \%$ elevations were recorded.

When the growth pattern was estimated $P$. reticulata showed isometric growth at 540 and 900 ppm levels while $B$. splendens showed isometric growth in all hardness levels. (Table 1).

Table 1 Growth performance and reproductive potential of . reticulata and B. splendens under varying hard water treatment

\begin{tabular}{|c|c|c|c|c|}
\hline & \multicolumn{4}{|c|}{ Growth performance } \\
\hline & 150 ppm (control) & $320 \mathrm{ppm}$ & 540 ppm & 900 ppm \\
\hline \multicolumn{5}{|l|}{ Weight gain (g) } \\
\hline P. reticulata $(\mathrm{N}=30)$ & $0.685^{b} \pm 0.058$ & $0.742^{b} \pm 0.075$ & $0.772^{\mathrm{a}, \mathrm{b}} \pm 0.091$ & $0.887^{\mathrm{a}} \pm 0.107$ \\
\hline B. splendens $(\mathrm{N}=20)$ & $1.730^{\mathrm{a}} \pm 0.124$ & $1.702^{\mathrm{a}} \pm 0.049$ & $1.796^{\mathrm{a}} \pm 0.066$ & $1.774^{\mathrm{a}} \pm 0.167$ \\
\hline \multicolumn{5}{|l|}{ Length gain $(\mathrm{cm})$} \\
\hline P. reticulate $(\mathrm{N}=30)$ & $3.25^{b} \pm 0.03$ & $3.31^{b} \pm 0.04$ & $3.31^{b} \pm 0.05$ & $3.49^{\mathrm{a}} \pm 0.02$ \\
\hline B. splendens $(\mathrm{N}=20)$ & $3.77^{\mathrm{a}} \pm 0.20$ & $3.93^{\mathrm{a}} \pm 0.31$ & $3.92^{\mathrm{a}} \pm 0.24$ & $4.01^{\mathrm{a}} \pm 0.31$ \\
\hline \multicolumn{5}{|l|}{ Larval length gain (mm) } \\
\hline $\begin{array}{l}\text { P. reticulata } \\
(\mathrm{N}=12)\end{array}$ & $16.67^{b} \pm 0.07$ & $18.16^{b} \pm 0.05$ & $19.33^{b} \pm 0.03$ & $21.83^{\mathrm{a}} \pm 0.03$ \\
\hline \multirow[t]{3}{*}{ B. splendens $(\mathrm{N}=12)$} & $7.67^{\mathrm{a}} \pm 0.57$ & $9.67^{\mathrm{a}} \pm 0.57$ & $7.33^{\mathrm{a}} \pm 0.57$ & $6.33^{\mathrm{a}} \pm 0.57$ \\
\hline & \multicolumn{4}{|c|}{ Reproductive dynamics } \\
\hline & 150 ppm & 320 ppm & 540 ppm & 900 ppm \\
\hline \multicolumn{5}{|l|}{ GSI } \\
\hline P. reticulate $(N=12)$ & $1.35^{b} \pm 0.39$ & $1.38^{\mathrm{b}} \pm 0.54$ & $1.50^{\mathrm{b}} \pm 0.66$ & $2.48^{\mathrm{a}} \pm 0.60$ \\
\hline B. splendens $(\mathrm{N}=12)$ & $17.01^{\mathrm{a}} \pm 1.15$ & $15.03^{\mathrm{a}} \pm 2.61$ & $17.25^{\mathrm{a}} \pm 4.41$ & $15.83^{\mathrm{a}} \pm 1.33$ \\
\hline \multicolumn{5}{|l|}{ Fecundity } \\
\hline P. reticulate $(\mathrm{N}=6)$ & $8.80^{b} \pm 2.59$ & $9.00^{b} \pm 3.54$ & $9.80^{a, b} \pm 4.32$ & $16.20^{\mathrm{a}} \pm 3.90$ \\
\hline B. splendens $(\mathrm{N}=6)$ & $743.3^{\mathrm{a}} \pm 83.3$ & $605^{a} \pm 179$ & $824^{a} \pm 175$ & $694^{a} \pm 272$ \\
\hline \multicolumn{5}{|l|}{ Bubble nest $\left(\mathrm{cm}^{2}\right)$} \\
\hline B. splendens $(\mathrm{N}=5)$ & $108.58^{\mathrm{a}} \pm 16.19$ & $74.3^{\mathrm{a}} \pm 24.5$ & $36.8^{b} \pm 19$ & $26.5^{b} \pm 22.2$ \\
\hline \multicolumn{5}{|l|}{ Hatchability } \\
\hline B. splendens $(N=12)$ & $78.1^{\mathrm{a}} \pm 17.6$ & $85.72^{\mathrm{a}} \pm 3.52$ & $29.02^{b} \pm 10.32$ & $24.89^{b} \pm 3.42$ \\
\hline \multicolumn{5}{|l|}{ Fertility } \\
\hline P. reticulate $(\mathrm{N}=12)$ & $73.89^{\mathrm{a}} \pm 7.70$ & $80.56^{a} \pm 5.78$ & $83.77^{a} \pm 3.13$ & $87.77^{a} \pm 4.75$ \\
\hline
\end{tabular}

$\mathrm{N}$ values represent the number of fishes in each dose

$a, b$ Value denoted by the same alphabetic superscript were not significantly differed from each other 


\section{Reproductive potential of exposed fishes}

Reproductive potential of $P$. reticulata showed significant variations in GSI, fecundity, bubble nest surface area, hatchability, fertility, under varying hardness levels. GSI of $P$. reticulata was increased with the hardness reporting a significantly higher value (Table $1, \mathrm{p}=0.016$ ) at 900 ppm. However, GSI of B. splendens lowered though not significant with the treatment (Table $1, \mathrm{p}=0.731$ ).

Fecundity of $P$. reticulata was increased with the water hardness, reporting a significantly higher value at 900 ppm. (16.20 $\pm 3.90, \mathrm{p}=0.016)$. Unlike the fecundity of $P$. reticulata, that of $B$. splendens was declined slightly by hardness treatment, showing only a slight elevation in 540 ppm (824 \pm 175 eggs compared to 743 at the control, Fig. 1).

Bubble nest surface area of B. splendens showed significant decline along the hardness series, reporting $75 \%$ decline at $900 \mathrm{ppm}$ (Table 1). In the hard water, 540 and 900 ppm, bubbles were blasted, and male fish was unable to rebuild the nest.

Fertility of $P$ reticulata, was increased along the hardness series, reporting $88 \%$ in 900 ppm compared to $74 \%$ at the control, though the increment was not significant ( $p>0.05)$. Hatchability of B. splendens declined significantly in higher hardness levels above 540 ppm reporting only $25 \%$ success at $900 \mathrm{ppm}$ compared to $78 \%$ in the control $(p=0.006)$. The percentage larval survival of both species declined gradually with the increasing hardness level, reporting significant declines above $320 \mathrm{ppm}$ ( $\mathrm{p}<0.0009$ ). However, the larval growth of $P$. reticulata was improved by higher hardness levels reaching a significant growth at $900 \mathrm{ppm}(\mathrm{p}=0.006)$, though the effect on $B$. splendens larvae was insignificant.

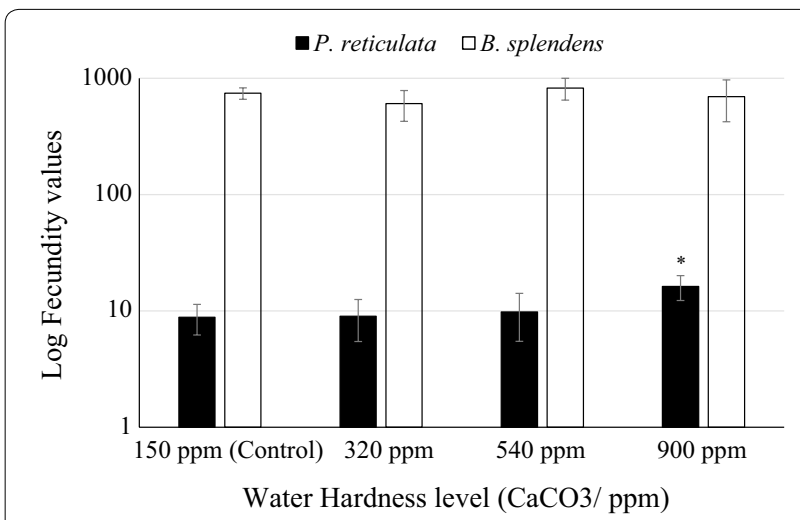

Fig. 1 Logarithmic values of the fecundity of $P$. reticulata and $B$. splendens under varying water hardness treatments (150-900 ppm). ( $N=6$ per each dose for each species were used for the analysis). Error bars represents standard error of mean. Asterisk indicates the significant alteration from the control $(p<0.05$, One way ANOVA, general linear model)

\section{Discussion}

$P$. reticulata and $B$. splendens displayed varying growth and reproductive potentials under different water hardness conditions. Growth (body weight and length) and the reproductive potential (gonadosomatic index, fecundity, bubble nest diameter, fertility) of $P$. reticulata were improved while most of those parameters were lowered in B. splendens with increasing hardness levels. These observations are compatible with previously reported studies for ovoviviparous and oviparous fishes, conducted elsewhere [20, 21].

According to Shim and Ho [20], dissolved Calcium is essential for growth of live bearer (ovoviviparous) fish especially $P$. reticulata as they are native to hard waters. They also found that rearing $P$. reticulata in extreme water hardness $(2500 \mathrm{ppm})$ showed 10 times higher weight gain than in soft water (167 ppm). In the same way, James and Sampath [21] found that Xiphophorus helleri (live bearer) reared in 1018 ppm hardness level exhibited better growth performance compared to 76 ppm level. Water hardness influenced growth performances of $P$. reticulata were further reiterated by weight and length relationship, which revealed isometric growth occurred only above $540 \mathrm{ppm}$ level. On the other hand, increasing water hardness showed no apparent effect on B. splendens resulting isometric growth in all hardness levels. Similarly, common snook Centropomus undecimalis and largemouth bass Micropterus salmoides exposed to higher hardness showed no considerable increase in growth parameters compared to their counter parts [3, $4]$.

Reproduction of $P$. reticulata was enhanced showing faster sexual maturation, in higher hardness conditions in compliance with James and Sampath [21] and Stratton [22], who reported higher and faster sexual maturation of $X$. helleri, in exceptionally high hardness medium. In line with this observation, Shim and Ho, [20] suggested that dissolved calcium is essential for sexual maturation of $P$. reticulata. As an oviparous fish, $B$. splendens showed slightly lowered reproductive potential under higher hardness levels. This is reiterated by previous work, Ratinam [8] who found suppressed gonadal development and maturity of Pterophyllum scalare and aborted maturation in Barbus conchonius and Barbus letrazona beyond 120 ppm hardness. Further, in compliance with previous studies, it was observed that high calcium in hard water deposit on the surface of the eggs of B. splendens, blocking the water absorbed into the perivitelline $[7,23]$ leading to dehydration and shrinking of the eggs [6]. Thus, being an oviparous fish B. spledens is suitable to the soft water than the hard water environment.

Increasing hardness caused high mortality in larvae of both species. Newborn are unable to tolerate 
the adverse environmental factors like extreme hard water [24] due to the stress condition in the physiology created by excess amount of calcium. Numerous studies carried on various fish species; Clarias gariepinus, Atlantic salmon (Salmo salar), rainbow trout (Oncorhynchus mykiss), and brown trout (Salvelinus fontinails), Rutilus frisii kutum (kutum), reiterated this finding $[6,7,25,26]$. Thus, soft water is preferable for larval rearing for both $P$. reticulata and $B$. splendens.

Hence, it may conclude that $P$. reticulata requires more calcium for the growth and reproduction than $B$. splendens which grow and reproduce well in soft water environment. Besides their popularity in aquarium trade, $P$. reticulata and $B$. splendens are used as effective larvivorous species in the biological control of Aedes aegypti (dengue mosquito) in many parts of the world [27]. Thus, understanding their growth and reproductive potential in natural waters with varying hardness levels may provide valuable guidance to their integrated approaches.

\section{Limitations}

This study was not intended to describe mechanism/s of action of $\mathrm{CaCO}_{3}$ in mediating growth and reproductive alteration of $P$. reticulata and $B$. splendens.

\section{Abbreviations \\ ANOVA: Analysis of variance; EDTA: Ethylenediaminetetraacetic acid; GSI: Gonadosomatic index; LWR: Length weight relationship.}

\section{Acknowledgements}

The authors acknowledge the Department of Bio Science, Faculty of Applied Science, Vavuniya Campus for providing facilities and the assistance.

\section{Author's contributions}

AK carried out the study under the guidance of PAES and UAJ. AK drafted the manuscript and UAJ and PAES reviewed it before the initial submission. All authors read and approved the final manuscript.

\section{Funding}

The study was conducted with the existing facilities of the Department of Bio Science, Faculty of Applied Science, Vavuniya Campus, and the Department's allocations were utilized for purchasing animals and consumables. Thus, no any other form of funding involved in the study.

\section{Availability of data and materials}

The datasets used and/or analyzed during the current study are available from the corresponding author on reasonable request.

\section{Ethics approval and consent to participate}

Ethical approval was obtained from the Research Ethics panel at the Department of Bio Science, Vavuniya Campus, University of Jaffna, Sri Lanka. Authors declare that the experiments conducted are complied with the standard animal care guidelines and the current laws of Sri Lanka.

\section{Consent for publication}

Not applicable.

\section{Competing interests}

The authors declare that they have no competing interests.

\section{Author details}

${ }^{1}$ Department of Bio Science, Faculty of Applied Science, Vavuniya Campus, University of Jaffna, Vavuniya, Sri Lanka. ${ }^{2}$ Department of Zoology, Faculty of Natural Sciences, The Open University of Sri Lanka, Colombo, Sri Lanka.

Received: 12 June 2020 Accepted: 10 November 2020

Published online: 19 November 2020

\section{References}

1. Wilkerling K. Platies for everyone. Trop Fish Hobby. 1992;41:8-21.

2. Blanksma C, Eguia B, Lott K, Lazorchak JM, Smith ME, Wratschko M, Dawson TD, Elonen C, Kahl M, Schoenfuss HL. Effects of water hardness on skeletal development and growth in juvenile fathead minnows. Aquaculture. 2009;286(3-4):226-32.

3. Michelotti BT, Passini G, Carvalho C, Salbego J, Mori NC, Rodrigues RV, Baldisserotto B, Cerqueira VR. Growth and metabolic parameters of common snook juveniles raised in freshwater with different water hardness. Aquaculture. 2018;1(482):31-5.

4. Romano N, Egnew N, Quintero H, Kelly A, Sinha AK. The effects of water hardness on the growth, metabolic indicators and stress resistance of largemouth bass Micropterus salmoides. Aquaculture. 2020;12:735469.

5. Lee CS, Hu F. Influences of Ca and Mg ions on the egg survival of grey mullet, Mugil cephalus L. J Fish Biol. 1983;22(1):13-20.

6. Gonzal AC, Aralar EV, Pavico JM. The effects of water hardness on the hatching and viability of silver carp (Hypophthalmichthys molitrix) eggs. Aquaculture. 1987;64(2):111-8.

7. Ketola HG, Longacre D, Greulich A, Phetterplace L, Lashomb R. High calcium concentration in water increases mortality of salmon and trout eggs. Progress Fish-Cult. 1988;50(3):129-35.

8. Rathinam K (1993) Influence of certain environmental factors on growth and breeding of ornamental fishes. B.F.Sc., Thesis submitted to Tamil Nadu Veterinary and Animal Sciences University, Tuticorin, pp. 18-27

9. Boyd CE, Tucker CS. Pond aquaculture water quality management. Germany: Springer Science \& Business Media; 2012. p. 106-16.

10. Brown DJ, Lynam S. The effect of sodium and calcium concentrations on the hatching of eggs and the survival of the yolk sac fry of brown trout, Salmo trutta L. at low pH. J Fish Biol. 1981;19(2):205-11.

11. Piyasiri S, Senanayake I. Status of ground water in Vavuniya City, Sri Lanka with special reference to fluoride and hardness. Int J Multi Stud. 2016;3:25.

12. Apha A. Standard methods for the examination of water and wastewater, vol. 21. Washington DC: American Public Health Association; 2005. pp. 258-9.

13. Le Cren ED. The length-weight relationship and seasonal cycle in gonad weight and condition in the perch (Perca fluviatilis). J Anim Ecol. 1951;1:201-19.

14. Srikrishnan R, Hirimuthugoda N, Rajapakshe W. Evaluation of growth performance and breeding habits of fighting fish (Betta splendens) under 3 diets and shelters. Surv Fish Sci. 2017;3(2):50-65.

15. RALC (1981) Integrated Fish Farming. vol. 1. Regional Aquaculture Lead Center of China, Wuxi, People's Republic of China, Chapter 3, pp. 411

16. Stolk A (1951) Histo-endocrinological analysis of gestation phenomena in the cyprinodont Lebistes reticulatus Peters. I. Thyroid activity during pregnancy. In: Proc. Acad. Sci., Amsterdam. vol. 54, pp. 550-57

17. Snedecor GW. The comparison of two groups. In: Statistical methods, Chapter 4. USA: The lowa State College Press; 1963. p. 534.

18. Jayaprakash AA. Length weight relationship and relative condition in Cynoglossus macrostomus Norman and C. arel (Schneider). J Mar Biol Assoc India. 2001;43(12):148-54.

19. Zar JH. Biostatistical analysis. India: Pearson Education India; 1999.

20. Shim KF, Ho CS. Calcium and phosphorus requirements of guppy Poecilia reticulata. Bull Japan Soc Sci Fish (Japan). 1989;55:1947-53.

21. James R, Sampath K. Effect of water hardness on growth and reproductive potential in Xiphophorus helleri and Betta splendens. J Aquacult Trop. 2004;19:255.

22. Stratton RF. Secrets of the swordtail. Trop Fish Hobbyist. 1993:42:116-24.

23. Potts WT, Rudy PP. Water balance in the eggs of the Atlantic salmon Salmo salar. J Exp Biol. 1969;50(1):223-37. 
24. Chanu TI, Rawat KD, Sharma A, Das A, Devi BN. Effects of water hardness on egg hatchability and larval survival of aquarium fish, Danio rerio. J Aquacult. 2010;18:1-7.

25. Molokwu CN, Okpokwasili GC. Effect of water hardness on egg hatchability and larval viability of Clarias gariepinus. Aquacult Int. 2002;10(1):57-64.

26. Taghizadeh V, Imanpour M, Jahnbakhashi A. Effect of water hardness on growth, survival, hematocrit and some blood biochemical indices of kutum (Rutilus frisii kutum) fingerlings. Global Vet. 2013;10(1):22-5.

27. de Góes Cavalcanti LP, de Paula Júnior FJ, Pontes RJ, Heukelbach J, de Oliveira Lima JW. Survival of larvivorous fish used for biological control of Aedes aegypti larvae in domestic containers with different chlorine concentrations. J Med Entomol. 2009;46(4):841-4.

\section{Publisher's Note}

Springer Nature remains neutral with regard to jurisdictional claims in published maps and institutional affiliations.
Ready to submit your research? Choose BMC and benefit from:

- fast, convenient online submission

- thorough peer review by experienced researchers in your field

- rapid publication on acceptance

- support for research data, including large and complex data types

- gold Open Access which fosters wider collaboration and increased citations

- maximum visibility for your research: over $100 \mathrm{M}$ website views per year

At BMC, research is always in progress.

Learn more biomedcentral.com/submissions 